\title{
ANALISIS FAKTOR KETERATURAN KUNJUNGAN POSYANDU BALITA DAN STATUS GIZI BALITA BERDASARKAN BERAT BADAN/UMUR
}

\author{
Analysis Of The Factors Of The Regularity Of Visits Posyandu Toddlers And \\ Infants Nutritional Status Based On Weight/Age \\ Danik Riawati ${ }^{1}$, Ajeng Novita Sari ${ }^{2}$ \\ STIKES Mamba'ul 'Ulum Surakarta \\ (danikriawati@yahoo.co.id)
}

\begin{abstract}
ABSTRAK
Latar belakang : Pemantauan petumbuhan dan perkembangan balita dilakukan secara berkala dengan tujuan untuk mendeteksi lebih awal adanya gangguan pertumbuhan dan perkembangan balita. Hal ini dapat dikatakan bahwa dengan memanfaatkan farsilitas pelayanan posyandu dapat memantau perkembangan dan kondisi kesehatan balita secara berkesinambungan.

Tujuan Penelitian : Tujuan penelitian ini adalah untuk menganalisis faktor keteraturan kunjungan posyandu balita dan status gizi balita berdasarkan berat badan/umur.

Metode : Penelitian ini menggunakan desain penelitian deskriptif analitik dengan dengan pendekatan cross sectional. Populasi penelitian adalah semua balita berusia 0-59 bulan di Posyandu Ngudi Mulyo Dusun Kembu, Waru, Kebakramat, Karanganyar pada bulan September tahun 2018 yaitu sebanyak 42 responden. Teknik sampling yang digunakan adalah accidental sampling, dimana peneliti menggunakan sampel sebanyak 42 responden. Data diambil dengan menggunakan data sekunder. Analisa data menggunakan uji koefisien korelasi Kendal Tau.

Hasil : Sebagian besar umur balita yang berkunjung di Posyandu Ngudi Mulyo Dusun Kembu, Waru, Kebakramat, Karanganyar 12-36 bulan yaitu sebanyak 33 balita $(78,6 \%)$, berjenis kelamin perempuan sebanyak 28 balita $(66,7 \%)$, sebagian besar berkunjung secara teratur sebanyak 37 balita $(88,1 \%)$ yang terdiri dari balita dengan status gizi baik sebanyak 35 balita $(83,3 \%), 1$ balita $(2,4 \%)$ berstatus gizi kurang, dan 1 balita $(2,4 \%)$ berstatus gizi buruk. Hasil analisis uji koefisien korelasi Kendal Tau sebesar 0,668 dengan signifikansi 0,000. Nilai signifikansi $<0,05$, maka Ho ditolak dan Ha diterima.
\end{abstract}

Simpulan : Ada hubungan antara keteraturan kunjungan posyandu dan status gizi balita berdasarkan berat badan/umur di Posyandu Ngudi Mulyo Dusun Kembu, Waru, Kebakramat, Karanganyar.

Kata Kunci: Keteraturan kunjungan, posyandu, balita, status gizi 


\begin{abstract}
Background: Monitoring of growth and development of toddlers conducted periodically with the aim of detecting the early presence of impaired growth and development of toddlers. It can be said that by making use of farsilitas service of posyandu can monitor developments and toddler health conditions on an ongoing basis.
\end{abstract}

The purpose : the purpose of this research is to analyze the factors the regularity of visits posyandu toddlers and infants nutritional status based on weight/age.

Method: This research uses descriptive analytic design research with cross sectional approach. The population of the research was all toddlers aged 0-59 months at Posyandu Ngudi Mulyo Village Kembu, Waru, Kebakramat in September of the year 2018 that is as much as 42 respondents. The sampling technique used is to accidental sampling, where researchers use samples as much as 42 respondents. Data taken with the use of secondary data. Data analysis using correlation coefficient test Kendal Tau.

Result: Most of the aged toddlers who visit at Posyandu Ngudi Mulyo Village Kembu, Waru, Kebakramat, Karanganyar 12-36 months that is as much as 33 toddlers (78.6\%), female sex as much as 28 toddlers (66.7\%), mostly visiting on a regular basis as much as 37 toddler (88.1\%) consists of a toddler with a good nutritional status as much as 35 toddler (83,3\%), 1 toddler (2.4\%) underweigt status, and 1 toddler (2.4\%) has several underweight status. The results of the test analysis of the correlation coefficient are 0,668 with a significance of 0,000. Significance value <0,05, then Ho is reiected and Ha is accepted.

Conclusion: There is a connection between the regularity of visits posyandu and toddler nutrition status based on weight/age at Posyandu Ngudi Mulyo Village Kembu, Waru, Kebakramat, Karanganyar.

Keywords: the regularity of visits, posyandu, toddlers, nutritional status

\title{
PENDAHULUAN
}

Status gizi balita dapat diukur dengan indeks berat badan per umur $(\mathrm{BB} / \mathrm{U})$, tinggi badan per umur $(\mathrm{TB} / \mathrm{U})$ dan berat badan per tinggi badan $(\mathrm{BB} / \mathrm{TB})$. Hasil pengukuran status gizi PSG tahun 2016 dengan indeks $\mathrm{BB} / \mathrm{U}$ pada balita 0-59 bulan yaitu terdapat gizi buruk sebesar $3,4 \%$, gizi kurang sebesar $14,4 \%$ dan gizi lebih sebesar 1,5\% (Kemenkes RI, 2017). Berdasarkan hasil tersebut maka tenaga kesehatan khususnya bidan ikut berperan dalam menurunkan angka status gizi yang tergolong tidak normal (gizi kurang, gizi buruk dan gizi lebih). Upaya tersebut dengan cara melakukan pemantauan penimbangan berat badan balita secara teratur. Hal ini dapat mendeteksi dini pertumbuhan balita, sehingga dapat diketahui status gizi balita tersebut. Pemantauan pertumbuhan dilakukan pada usia anak 0-72 bulan melalui penimbangan berat badan setiap bulan dan pengukuran tinggi badan setiap 3 bulan serta pengukuran lingkar kepala sesuai jadwal (Menkes RI, 2014). Petumbuhan dan perkembangan balita sangat diperlukan 
pemantauan secara intensif supaya dapat terdeteksi lebih awal adanya gangguan pertumbuhan dan perkembangannya (Pusdiklatnakes Kemenkes RI, 2016).

Pemantauan pertumbuhan balita diatur dalam Peraturan Menteri Kesehatan Republik Indonesia No.66 tahun 2014 tentang pemantauan pertumbuhan perkembangan dan gangguan tumbuh kembang anak yaitu pada pasal 1 ayat 3 berbunyi "'balita adalah anak umur 12 bulan sampai dengan 59 bulan". Pasal 1 ayat 5 menjelaskan arti "pertumbuhan adalah bertambahnya ukuran dan jumlah sel serta jaringan interseluler, yang berrati bertambahnya ukuran fisik dan struktur sebagian atau keseluruhan, sehingga dapat diukur dengan satuan panjang dan berat". Pemantauan petumbuhan dan perkembangan balita dapat dilakukan di Posyandu (Pos Pelayanan Terpadu). Posyandu merupakan salah satu bentuk Upaya Kesehatan Masyarakat Bersumberdaya Masyarakat (UKBM) yang dikelola dari, oleh, untuk dan bersama masyarakat untuk memberdayakan masyarakat dan memberikan kemudahan kepada masyarakat untuk memperoleh pelayanan kesehatan dasar bagi ibu, bayi dan anak balita (Kemenkes RI, 2012). Beberapa faktor yang mempengaruhi kualitas pertumbuhan dan perkembangan anak yaitu faktor internal dan faktor eksternal. Faktor internal sepeti ras/bangsa, keluarga, umur, jenis kelamin, genetik dan kelainan kromosom. Faktor eksternal seperti faktor prenatal, faktor persalinan, dan faktor pascasalin (Pusdiklatnakes Kemenkes RI, 2016). Penelitian terdahulu yang telah dilakukan oleh Danik pada tahun 2017 di Posyandu wilayah Mojosongo Jebres Surakarta didapatkan bahwa sebagian besar pertumbuhan balita di Posyandu wilayah Mojosongo termasuk kategori gizi baikyitu mencapai 80,5\%, tegolong gizi lebih sebanyak 2,4\% serta masih terdapat gizi kurang sebanyak $17,1 \%$.

Studi pendahuluan yang dilakukan di Posyandu Ngudi Mulyo Dusun Kembu, Waru, Kebakramat masih ada bayi balita yang tidak teratur berkunjung ke Posyandu. Berdasarkan hal diatas maka peneliti tertarik mengambil judul "Analisis Faktor Keteraturan Kunjungan Posyandu Balita Dan Status Gizi Balita Berdasarkan Berat Badan/Umur”.

\section{METODE PENELITIAN}

Penelitian ini merupakan penelitian deskriptif analitik dengan dengan pendekatan cross sectional. Populasi penelitian adalah semua balita di Posyandu Ngudi Mulyo Dusun Kembu, Waru, Kebakramat, Karanganyar pada bulan September tahun 2018 sebanyak 42 responden. Subyek penelitian ini adalah semua bayi balita yang berkunjung di Posyandu Ngudi Mulyo Dusun Kembu, Waru, Kebakramat pada bulan September 2018 sebanyak 42 balita.

Alat pengumpulan data menggunakan master tabel. Metode pengumpulan data menggunakan data sekunder diperoleh dari buku register balita dan buku KIA. Teknik sampling yang digunakan adalah accidental sampling, dimana peneliti menggunakan sampel sebanyak 42 responden. Analisa data menggunakan Korelasi Kendall Tau. 


\section{HASIL PENELITIAN DAN PEMBAHASAN}

Tabel 1 Distribusi frekuensi karakteristik balita berdasarkan umur dan jenis kelamin

\begin{tabular}{lcc}
\hline \multicolumn{1}{c}{ Karakteristik } & frekuensi & Prosentase (\%) \\
\hline Umur & 33 & 78,6 \\
12-36 bulan & 9 & 21,4 \\
37-60 bulan & 42 & 100 \\
$\quad$ Total & & \\
Jenis kelamin & 14 & 33,3 \\
Laki-laki & 28 & 66,7 \\
perempuan & 42 & 100 \\
\multicolumn{1}{r}{$\quad$ Total } &
\end{tabular}

Sumber data primer: September 2018

Berdasarkan tabel 1 didapatkan bahwa sebagian besar balita yang berkunjung di Posyandu Ngudi Mulyo Dusun Kembu, Waru, Kebakramat, Karanganyar berumur 12-36 bulan yaitu sebanyak 33 balita $(78,6 \%)$ dan umur 37-60 bulan sebanyak 9 balita $(21,4 \%)$. Balita yang memiliki jenis kelamin laki-laki sebanyak 14 balita $(33,3 \%)$ dan perempuan sebanyak 28 balita $(66,7 \%)$

Tabel 2 Distribusi frekuensi keteraturan kunjungan posyandu balita

\begin{tabular}{|c|c|c|}
\hline Keteraturan kunjungan posyandu & $\mathrm{f}$ & $\%$ \\
\hline Teratur & 37 & 88,1 \\
\hline Tidak teratur & 5 & 11,9 \\
\hline Total & 42 & 100 \\
\hline
\end{tabular}

Sumber data primer: September 2018

Berdasarkan tabel 2 didapatkan bahwa tingkat keteraturan kunjungan posyandu di Posyandu Ngudi Mulyo Dusun Kembu, Waru, Kebakramat, Karanganyar yaitu sebagian besar termasuk kategori teratur sebanyak 37 balita $(88,1 \%)$ dan masih terdapat balita yang berkunjung secara tidak teratur sebanyak 5 balita $(11,9 \%)$.

Tabel 3 Distribusi frekuensi status gizi balita berdasarkan BB/U

\begin{tabular}{|c|c|c|}
\hline Status gizi balita & $\mathrm{f}$ & $\%$ \\
\hline Gizi buruk & 2 & 4,8 \\
\hline Gizi kurang & 4 & 9,5 \\
\hline Gizi baik & 36 & 85,7 \\
\hline Gizi lebih & 0 & 0 \\
\hline Total & 42 & 100 \\
\hline
\end{tabular}

Sumber data primer: September 2018 
Tabel 3 menunjukkan bahwa sebagian besar balita di Posyandu Ngudi Mulyo Dusun Kembu, Waru, Kebakramat, Karanganyar memiliki status gizi baik yaitu sebanyak 36 balita $(85,7 \%)$ dan masih terdapat 4 balita $(9,5 \%)$ yang termasuk kategori gizi kurang serta 2 balita $(4,8 \%)$ termasuk kategori gizi buruk.

Tabel 4 Analisis faktor keteraturan kunjungan posyandu balita dengan status gizi balita

\begin{tabular}{|c|c|c|c|c|c|c|c|c|c|c|}
\hline \multirow{3}{*}{$\begin{array}{l}\text { Keteraturan } \\
\text { Kunjungan } \\
\text { Ke Posyandu }\end{array}$} & \multicolumn{8}{|c|}{ Status gizi balita } & \multirow{2}{*}{\multicolumn{2}{|c|}{ Jumlah }} \\
\hline & \multicolumn{2}{|c|}{ Buruk } & \multicolumn{2}{|c|}{ Kurang } & \multicolumn{2}{|c|}{ Baik } & \multicolumn{2}{|c|}{ Lebih } & & \\
\hline & $\mathrm{f}$ & $\%$ & $\mathrm{f}$ & $\%$ & $\mathrm{f}$ & $\%$ & $\mathrm{f}$ & $\%$ & $\mathrm{f}$ & $\%$ \\
\hline Teratur & 1 & 2,4 & 1 & 2,4 & 35 & 83,3 & 0 & 0 & 37 & 88,1 \\
\hline Tidak teratur & 1 & 2,4 & 3 & 7,1 & 1 & 2,4 & 0 & 0 & 5 & 11,9 \\
\hline Total & 2 & 4,8 & 4 & 9,5 & 36 & 85,7 & 0 & 0 & 42 & 100 \\
\hline
\end{tabular}

Sumber data primer: September 2018

Berdasarkan tabel 4 didapatkan bahwa keteraturan kunjungan Posyandu dan status gizi balita di Posyandu Ngudi Mulyo Dusun Kembu, Waru, Kebakramat, Karanganyar didapatkan bahwa sebagian besar balita yang berkunjung ke Posyandu secara teratur sebanyak 37 balita $(88,1 \%)$ yang terdiri dari sebagian besar balita dengan status gizi baik sebanyak 35 balita $(83,3 \%), 1$ balita $(2,4 \%)$ berstatus gizi kurang, dan balita $(2,4 \%)$ berstatus gizi buruk.

Balita yang berkunjung tidak teratur sebanyak 5 balita $(11,9 \%)$ yang terdiri dari balita dengan status gizi baik sebanyak 1 balita $(2,4 \%), 3$ balita $(7,1 \%)$ berstatus gizi kurang dan 1 balita $(2,4 \%)$ memiliki status gizi buruk.

Tabel 5 Analisa Bivariat Kendal Tau Analisis Faktor Keteraturan Kunjungan Posyandu Balita Dengan Status Gizi Balita

\begin{tabular}{|c|c|c|c|c|}
\hline \multicolumn{5}{|c|}{ Correlations } \\
\hline & & & Keteraturan & Status \\
\hline \multirow{6}{*}{$\begin{array}{l}\text { Kendall's } \\
\text { tau_b }\end{array}$} & & & Keteraturan & Status \\
\hline & Keteraturan & Correlation Coefficient & 1.000 & $.668^{* *}$ \\
\hline & & Sig. (2-tailed) & . & .000 \\
\hline & Status & $\mathrm{N}$ & 42 & 42 \\
\hline & & Correlation Coefficient & $.668^{* *}$ & 1.000 \\
\hline & & Sig. (2-tailed) & .000 & . \\
\hline
\end{tabular}

**. Correlation is significant at the 0.01 level (2-tailed).

Tabel 5 didapatkan bahwa hasil analisis uji koefisien korelasi Kendal Tau sebesar 0,668 dengan signifikansi 0,000. Nilai signifikansi <0,05, maka Ho ditolak dan Ha diterima. Artinya terdapat hubungan antara keteraturan kunjungan posyandu dan status gizi balita berdasarkan berat badan/umur di Posyandu Ngudi Mulyo Dusun Kembu, Waru, Kebakramat, Karanganyar. Hubungan kedua variabel kuat. 
Hasil penelitian pada tabel 1 didapatkan bahwa balita yang berkunjung di Posyandu Ngudi Mulyo Dusun Kembu, Waru, Kebakramat, Karanganyar sebagian besar berumur 12-36 bulan yaitu sebanyak 33 balita $(78,6 \%)$ dan umur 37-60 bulan sebanyak 9 balita (21,4\%). Balita yang memiliki jenis kelamin perempuan sebanyak 28 balita (66,7\%) dan laki-laki sebanyak 14 balita (33,3\%). Menurut teori, balita adalah anak umur 12 bulan sampai dengan 59 bulan (Menkes RI, 2014). Para ahli juga mengatakan bahwa usia balita sebagai tahapan perkembangan anak yang cukup rentan terhadap berbagai serangan penyakit, termasuk penyakit kekurangan atau kelebihan asupan nutrisi (Pusat Data dan Informasi Kementria Kesehatan RI, 2015). Bayi, balita dan anak prasekolah termasuk salah satu kelompok yang rawan gizi, sehingga ibu balita perlu memeriksakan anaknya ke posyandu karena posyandu merupakan farsilitas kesehatan dasar yang didalamnya juga ada Komunikasi, Informasi dan Edukasi (KIE) tentang kesehatan ibu balita yang di berikan oleh tenaga kesehatan.

Berdasarkan tabel 2 didapatkan bahwa tingkat keteraturan kunjungan posyandu di Posyandu Ngudi Mulyo Dusun Kembu, Waru, Kebakramat, Karanganyar sebagian besar termasuk kategori teratur yaitu sebanyak 37 balita $(88,1 \%)$ dan masih terdapat balita yang berkunjung secara tidak teratur sebanyak 5 balita $(11,9 \%)$. Hal ini menunjukkan bahwa ibu yang berkunjung teratur ke posyandu, maka akan mendapatkan informasi penting tentang tumbuh kembang balita. Petumbuhan dan perkembangan balita sangat diperlukan pemantauan secara berkala supaya dapat terdeteksi lebih awal adanya gangguan pertumbuhan dan perkembangannya (Pusdiklatnakes Kemenkes RI, 2016). Pemantauan petumbuhan dan perkembangan balita dapat dilakukan di Posyandu (Pos Pelayanan Terpadu), karena posyandu merupakan salah satu bentuk Upaya Kesehatan Masyarakat Bersumberdaya Masyarakat (UKBM) yang dikelola dari, oleh, untuk dan bersama masyarakat untuk memberdayakan masyarakat dan memberikan kemudahan kepada masyarakat untuk memperoleh pelayanan kesehatan dasar bagi ibu, bayi dan anak balita (Kemenkes RI, 2012). Penelitian ini sejalan dengan penelitian Tumbol J dkk tahun 2013 didapatkan bahwa jumlah anak dan pendapatan ibu yang memiliki anak balita mempunyai hubungan yang bermakna secara statistik $(\mathrm{P}<0,05)$ dengan frekuensi kunjungan ibu yang memiliki anak balita di Posyandu Kelurahan Lewet Amurang Timur.

Tabel 3 menunjukkan bahwa sebagian besar balita di Posyandu Ngudi Mulyo Dusun Kembu, Waru, Kebakramat, Karanganyar memiliki status gizi baik yaitu sebanyak 36 balita $(85,7 \%)$ dan masih terdapat 4 balita $(9,5 \%)$ yang termasuk kategori gizi kurang serta 2 balita $(4,8 \%)$ termasuk kategori gizi buruk. Hal ini menunjukan bahwa masih terdapat balita yang status gizi dibawah nilai status gizi normal yaitu kurang dari -2SD sampai dengan 2SD. Berdasarkan hal tersebut maka tenaga kesehatan harus lebih ekstra memperhatian pada balita tersebut dan ibu balita dengan memberikan konseling tentang pemenuhan nutrisi bagi balita. Pertumbuhan dan perkembangan balita sangat dipengaruhi oleh pemenuhan gizi sejak hamil bahkan sejak calon ibu remaja dan stimulasi sejak dalam kandungan (Pusdiklatnakes Kemenkes RI, 2016). Menurut Riawati dan Suparti dalam penelitiannya menunjukkan bahwa terdapat hubungan yang 
signifikan antara kenaikan berat badan bayi baru lahir dengan kenaikan berat badan ibu selama kehamilan.

Status gizi balita dapat diukur dengan indeks berat badan per umur $(\mathrm{BB} / \mathrm{U})$, tinggi badan per umur $(\mathrm{TB} / \mathrm{U})$ dan berat badan per tinggi badan $(\mathrm{BB} / \mathrm{TB})$, sehingga penimbangan balita secara teratur dapat memantau secara intensif adanya kenaikan atau penurunan berat badan balita (Kemenkes RI, 2017). Kualitas tumbuh kembang anak dipengaruhi oleh dua faktor yaitu faktor internal dan faktor eksternal. Faktor internal sepeti ras/bangsa, keluarga, umur, jenis kelamin, genetik dan kelainan kromosom. Faktor eksternal seperti faktor prenatal, faktor persalinan, dan faktor pascasalin (Pusdiklatnakes Kemenkes RI, 2016). Faktor lain yang juga berpengaruh yaitu kuantitas dan kualitas makanan dan minuman yang di konsumsi akan mempengaruhi asupan gizi sehingga mempengaruhi kesehatan individu dan masyarakat. Upaya pencegahan yang dilakukan tenaga kesehatan untuk menanggani masalah gizi pada balita antara lain sosialisasi pedoman gizi seimbang sebagai panduan makan, beraktifitas fisik, hidup bersih dan memantau berat badan secara teratur untuk mempertahankan berat badan normal. Hal ini dikarenakan gizi yang optimal sangat penting untuk pertumbuhan dan perkembangan fisik, dan kecerdasan bayi, anak-anak serta seluruh kelompok umur. Gizi yang baik membuat berat badan normal dan sehat, tubuh tidak mudah terkena penyakit, produktivitas kerja meningkat dan kematian dini (Menkes, 2014). Menurut penelitian Fitria dan Azmi tahun 2014 didapatkan bahwa ada hubungan pemanfaat posyandu dengan status gizi balita ( $\mathrm{p}$ value 0,000). Penelitian yang telah dilakukan oleh Riawati dan Hanifah didapatkan bahwa sebagian besar pertumbuhan balita di posyandu wilayah Mojosongo termasuk kategori gizi baik yaitu mencapai 80,5\%, tegolong gizi lebih sebanyak $2,4 \%$ serta masih terdapat gizi kurang sebanyak 17,1\%. Berdasarkan hasil penelitian tesebut dikarenakan kader dan petugas kesehatan dalam setiap kegiatan posyandu wilayah Mojosongo selalu ada KIE untuk ibu balita, sehingga ibu balita mendapatkan informasi tentang kesehatan yang benar.

Berdasarkan tabel 4 didapatkan bahwa keteraturan kunjungan Posyandu dan status gizi balita di Posyandu Ngudi Mulyo Dusun Kembu, Waru, Kebakramat, Karanganyar didapatkan bahwa sebagian besar balita yang berkunjung ke Posyandu secara teratur sebanyak 37 balita $(88,1 \%)$ yang terdiri dari sebagian besar balita dengan status gizi baik sebanyak 35 balita $(83,3 \%), 1$ balita $(2,4 \%)$ berstatus gizi kurang, dan balita $(2,4 \%)$ berstatus gizi buruk. Balita yang berkunjung tidak teratur sebanyak 5 balita $(11,9 \%)$ yang terdiri dari balita dengan status gizi baik sebanyak 1 balita $(2,4 \%), 3$ balita $(7,1 \%)$ berstatus gizi kurang dan 1 balita $(2,4 \%)$ memiliki status gizi buruk. Berdasarkan hal tersebut, maka dapat diketahui bahwa balita yang berkunjung ke posyandu secara teratur dapat dipantau tumbuh kembangnya dan apabila terdapat penyimpangan dapat segera dilakukan tindak lanjut dengan memberikan penyuluhan, pemberian makanan tambahan dan memberikan suplemen gizi. Deteksi penyimpangan pertumbuhan ini digunakan untuk mengetahui status gizi balita termasuk kategori kurang/buruk dan mikro/makrosefali. (Pusdiklatnakes Kemenkes RI, 2016). Status gizi balita dapat diukur dengan indeks berat badan per umur $(\mathrm{BB} / \mathrm{U})$, tinggi badan per umur $(\mathrm{TB} / \mathrm{U})$ dan berat badan per tinggi badan $(\mathrm{BB} / \mathrm{TB})$. Menurut hasil pengukuran 
status gizi PSG tahun 2016 dengan indeks BB/U pada balita 0-59 bulan yaitu terdapat gizi buruk sebesar 3,4\%, gizi kurang sebesar 14,4\% dan gizi lebih sebesar 1,5\% (Kemenkes RI, 2017).

Kualitas tumbuh kembang anak di pengaruhi oleh faktor internal dan faktor eksternal. Faktor internal sepeti ras/bangsa, keluarga, umur, jenis kelamin, genetik dan kelainan kromosom. Faktor eksternal seperti faktor prenatal, faktor persalinan, dan faktor pascasalin (Pusdiknakes Kemenkes RI, 2016). Menurut penelitian Sugiyarti dkk didapatkan bahwa hasil analisis statistik kendal tau nilai z hitung $\geq$ ztabel yaitu $0,614 \geq 0,185$ yang membuktikan bahwa adanya hubungan antara tingkat kepatuhan kunjungan posyandu dengan status gizi.

Berdasarkan tabel 5 didapatkan bahwa hasil analisis uji koefisien korelasi Kendal Tau sebesar 0,668 dengan signifikansi 0,000. Nilai signifikansi <0,05, maka Ho ditolak dan Ha diterima. Artinya terdapat hubungan antara keteraturan kunjungan posyandu dan status gizi balita berdasarkan berat badan/umur di Posyandu Ngudi Mulyo Dusun Kembu, Waru, Kebakramat, Karanganyar. Hubungan kedua variabel kuat. Hasil penelitian ini menunjukkan bahwa terdapat hubungan antara keteraturan kunjungan posyandu dengan status gizi balita. Hal ini membuktikan bahwa dengan semakin teratur berkunjung ke posyandu maka status gizi balita akan menjadi lebih baik dan mudah terdeteksi adanya penyimpangan pertumbuhan serta sebaliknya yang tidak teratur berkunjung ke posyandu maka status gizi balita sulit terdeteksi kondisi balita. Penelitian ini sejalan dengan penelitian Lanoh M dkk tahun 2015 didapatkan hasil terdapat hubungan antara pemanfaatan posyandu dengan status gizi.

\section{SIMPULAN DAN SARAN}

\section{Simpulan}

Sebagian besar balita yang berkunjung di Posyandu Ngudi Mulyo Dusun Kembu, Waru, Kebakramat, Karanganyar sebagian besar berumur 12-36 bulan yaitu sebanyak 33 balita $(78,6 \%)$ dan rata-rata berjenis kelamin perempuan sebanyak 28 balita $(66,7 \%)$.

Sebagian besar balita yang berkunjung ke Posyandu secara teratur sebanyak 37 balita $(88,1 \%)$ yang terdiri dari sebagian besar balita dengan status gizi baik sebanyak 35 balita $(83,3 \%), 1$ balita $(2,4 \%)$ berstatus gizi kurang, dan balita $(2,4 \%)$ berstatus gizi buruk. Balita yang berkunjung tidak teratur sebanyak 5 balita $(11,9 \%)$ yang terdiri dari balita dengan status gizi baik sebanyak 1 balita $(2,4 \%), 3$ balita $(7,1 \%)$ berstatus gizi kurang dan 1 balita $(2,4 \%)$ memiliki status gizi buruk.

Hasil koefisien korelasi Kendal Tau dengan nilai signifikaan $<0,05$ yaitu sebanyak 0, 668 yang membuktikan bahwa adanya hubungan yang kuat antara keteraturan kunjungan posyandu dengan status gizi balita.

\section{Saran}

Bagi Posyandu Ngudi Mulyo Dusun Kembu, Waru, Kebakramat, Karanganyar diharapkan hasil penelitian ini dapat sebagai dalam memberikan pelayanan. Bagi tenaga kesehatan dan Kader Posyandu supaya lebih 
meningkatkan pelayanannya dan bersedia meluangkan waktu untuk memantau balita yang tidak teratur kunjungan Posyandu. Bagi orang tua yang memiliki bayi balita diharapkan teratur untuk berkunjung ke posyandu supaya dapat memantau tumbuh kembang balita..

\section{DAFTAR PUSTAKA}

Fitria dan Azmi N, 2014. Hubungan Pemanfaat Posyandu dengan satus gizi balita di Kecamatan Kota Jantho. Nursing Journal. ISSN: 2087-2879. Volume VI No. 1 2015. http://jurnal.unsyiah.ac.id/INJ/article/view/6630. Diakses pada tanggal 15 November 2018, jam 09.00 WIB.

Kemenkes RI. 2011. Keputusan Menteri Kesehatan Republik Indonesia No.1995/MENKES/SK/XII/2010 tentang Standar Antropometri Penilaian Status Gizi Anak. Jakarta: Kementrian Kesehatan RI Direktorat Jendral Bina Gizi dan Kesehatan Ibu dan Anak Direktorat Bina Gizi.

Kemenkes RI. 2014. Pedoman Gizi Seimabang. Jakarta: Kemenkes RI. http://gizi.depkes.go.id/download/Pedoman\%20Gizi/PGS\%20Ok.pdf.

Diakses pada tanggal 15 November 2018, jam 09.00 WIB..

Kemenkes RI. 2017. Buku Kesehatan Ibu dan anak. Jakarta: Kemenkes RI.

Kemenkes RI. 2017. Profil Kesehatan Indonesia Tahun 2016. Jakarta: Kemenkes RI. http://www.depkes.go.id/resources/download/pusdatin/profil-kesehatanindonesia/Profil-Kesehatan-Indonesia-2016.pdf. Diakses pada tanggal 15 November 2018, jam 09.00 WIB..

Lanoh M dkk, 2015. Hubungan Pemanfaatan Posyandu Dengan Status Gizi Balita Di Wilayah Kerja Puskesmas Ranotana Weru Kota Menado. https://ejournal.unsrat.ac.id/index.php/jkp/article/viewFile/8176/7729.

EJournal Keperawatan (E-Kp) Volume 3 Nomor 2, Mei 2015. Diakses Pada Tanggal 15 November 2018, jam 09.00 WIB.

Menkes RI, 2014. Peraturan Menteri Kesehatan Republik Indonesia No. 41 Tahun 2014 Tentang Pedoman Gizi Seimbang. http://gizi.depkes.go.id/download/Pedoman\%20Gizi/PGS\%20Ok.pdf.

Diakses pada tanggal 15 November 2018, jam 09.00 WIB.

Menkes RI, 2014. Peraturan Menteri Kesehatan Republik Indonesia No. 66 Tahun 2014 tentang Pemantauan Pertumbuhan Perkembangan Dan Gangguan Tumbuh Kembang Anak. http://kesga.kemkes.go.id/images/pedoman/PMK\%20No.\%2066\%20ttg\%20 Pemantauan\%20Tumbuh\%20Kembang\%20Anak.pdf. Diakses pada tanggal 15 November 2018, jam 09.00 WIB.

Menkes RI, 2014. Peraturan Menteri Kesehatan Republik Indonesia No. 25 Tahun 2014 Tentang Upaya Kesehatan Anak. http://kesga.kemkes.go.id/images/pedoman/PMK\%20No.\%2025\%20ttg\%20 Upaya\%20Kesehatan\%20Anak.pdf. Diakses pada tanggal 15 November 2018, jam 09.00 WIB.

Menkes RI, 2017. Peraturan Menteri Kesehatan Republik Indonesia No.28 Tahun 2017 Tentang Izin Dan Penyelenggaraan Praktek Bidan. 
https://drive.google.com/file/d/0ByRIDMiFQLUAYzlJSENLa0hram8/view. Diakses pada tanggal 15November 2018, jam 09.00 WIB.

Pusdiklatnakes Kemenkes RI, 2016. Buku Ajar Kesehatan Ibu Dan Anak Continuum Of Carelife Cycle. Jakarta: Pusat Pendidikan dan Pelatihan Tenaga Kesehatan.

Pusat Data dan Informassi kementrian Kesehatan RI, 2015. Infodatin Situasi Kesehatan Anak Balita Di Indonesia. http://www.depkes.go.id/resources/download/pusdatin/infodatin/infodatinanak-balita.pdf. ISSN 2442-7659. Jakarta: Pusat Data dan Informassi kementrian Kesehatan RI. Diakses pada tanggal 15 November 2018, jam $09.00 \mathrm{WIB}$.

Riawati D dan Hanifah L, 2017. Evaluasi Pertumbuhan Balita Berdasarkan Umur dan Berat Badan.

http://jurnal.stikesmus.ac.id/index.php/JKebIn/article/download/18/17. Jurnal Kebidanan Indonesia Volume 8 No.2 Juli 2017. ISSN 2086-5562. Diakses pada tanggal 15 November 2018, jam 09.00 WIB.

Riawati D dan Suparti S, 2018. Analisis Faktor Berat Badan Bayi Baru Lahir Bedasarkan Kenaikan Berat Badan Ibu Selama Kehamilan. https://jurnal.stikesmus.ac.id/index.php/JKebIn/article/view/212. Jurnal Kebidanan Indonesia Volume 9 No.2 Juli 2018. ISSN 2579-7824. Diakses pada tanggal 15 November 2018, jam 09.00 WIB.

Sugiyarti dkk, 2014. Kepatuhan Kunjungan Posyandu Dengan Status Gizi Balita Di Posyandu Karangbendo Bangununtapan Bantul Yogyakarta. Journal Ners and Medwifery Indonesia. JKNI Volume 2 No.3 Tahun 2014. ISSN2354-7642.

https://www.researchgate.net/publication/307445297_Kepatuhan_Kunjunga n_Posyandu_dan_Status_Gizi_Balita_di_Posyandu_Karangbendo_Bangunt apan_Bantul_Yogyakarta. Diakses pada tanggal 15 November 2018, jam 09.00 WIB.

Tumbol J dkk, 2013. Faktor-faktor yang berhubungan dengan frekuensi kunjungan ibu yang memiliki anak balita ke Posyandu Kelurahan Lewet Kecamatan Amurang Timur Kabupaten Minahasa Selatan. https://media.neliti.com/media/publications/91872-ID-faktor-faktor-yangberhubungan-dengan-fr.pdf. Jurnal Ilmiah Bidan Volume 1 No.1 Bulan JuliDesember 2013. ISSN: 2339-1731. Diakses pada tanggal 15 November 2018, jam 09.00 WIB. 